\title{
An Analysis of Regularity in Fasting Blood Sugar Variations and Influence Factors After Kidney Transplantation
}

\author{
Zhufu Shao ${ }^{1, ~ *, ~ R u i r u i ~} \mathrm{Xu}^{2}$, Chunyan Yang ${ }^{1}$ \\ ${ }^{1}$ Department of Critical Care Medicine, Binzhou People's Hospital, Binzhou City, P. R. China \\ ${ }^{2}$ Department of Nephrology, Binzhou People's Hospital, Binzhou City, P. R. China
}

Email address:

shaozhufu2019@163.com (Zhufu Shao)

*Corresponding author

To cite this article:

Zhufu Shao, Ruirui Xu, Chunyan Yang. An Analysis of Regularity in Fasting Blood Sugar Variations and Influence Factors After Kidney Transplantation. Science Journal of Public Health. Vol. 7, No. 6, 2019, pp. 200-205. doi: 10.11648/j.sjph.20190706.14

Received: September 23, 2019; Accepted: October 31, 2019; Published: November 18, 2019

\begin{abstract}
Objective To discuss the regularity in fasting blood sugar variations following kidneytransplantation and evaluate the PTDM morbidity and the effect of fasting blood sugar on survival and complications of patients. Method 422 patients receiving kidneytransplantation in our hospital from January 2015 to December 2018 were collected. Based on the pre-operative fasting blood sugar, the patients were divided into Group DM, IFG, and NFG. The variation trends of fasting blood sugar in various groups were obtained by analysing the fasting blood sugar data of patients $3,6,9,12,24,36,48$, and 60 months before and after operation. The PTDM occurrence conditions were analysed 3, 6, 9, 12, 36, and 60 months after operation based on the fasting blood sugar of patients; a simplified OGTT was performed for patients with their fasting blood sugar not meeting the diagnostic criteria for diabetes $\geq 3$ years after kidneytransplantation to analyse the PTDM morbidity among patients $\geq 3$ years after kidneytransplantation and calculate the HOMA index. The patients were divided into Group DM, IFG, and NFG based on fasting blood sugar before kidneytransplantation and PTDM Group and Non-PTDM Group. A comparison was made for the difference in survival rate among various groups. Result The fasting blood sugar in the Group DM decreased significantly compared with that before operation $(\mathrm{P}<0.05)$; the fasting blood sugar in the Group IFG and NFG increased compared that before operation $(\mathrm{P}<0.05)$. The PTDM morbidity exhibited an overall decreasing trend with time and reached as high as $52.82 \% 3$ months after operation. HOMA-IR was the highest in Group IGR followed by Group PTDM. HOMA-IR significantly increased in Group IGR compared with the group of normal blood sugar $(\mathrm{P}<0.05)$. HOMA- $\beta$ in Group PTDM decreased significantly compared with the group of normal blood sugar and Group IGR $(\mathrm{P}<0.05)$. The survival rate in Group DM significantly decreased compared with that in Group NFG $(\mathrm{P}<0.05)$; the survival rate in Group IFG also decreased significantly compared with that in Group NFG $(\mathrm{P}<0.05)$; the average survival time and survival rate in Group PTDM were significantly lower than those in groups other than Group PTDM $(\mathrm{P}<0.05)$. Conclusion kidneytransplantation is able to improve the fasting blood sugar of patients with diabetes and the blood sugar can significant affect the survival rate of kidneytransplantation patients and lower the survival rate of patients.
\end{abstract}

Keywords: Kidneytransplantation, Fasting Blood Sugar, Post-Transplant Diabetes, Survival

\section{Introduction}

The number of kidneytransplantation patients has increased considerably with continuous popularization and maturation of the kidneytransplantation technique since the first kidneytransplantation was carried out in 1960s. The survival time of patients also extends accordingly due to the elevation of the survival rate during the perioperative period and maturation of application of anti-rejection medicine. Thus, increasing importance has been attached to the long-term complications and living quality of kidneytransplantation patients. Post-transplant Diabetes Mellitus (PTDM) has a huge impact on such complications as cardiovascular, infection, neuropsychiatric system etc., which may lead to a higher case fatality rate and affect the survival of transplants and the long-term survival of recipients [1]. The PTDM morbidity has been reported 
different, approximately 7.2-35\%, in various countries [2-3]. The hazards of PTDM have not been completely explained. Based on reports, hepatitis $\mathrm{C}$ virus (HCV) infection, aging, obesity, family history of diabetes, abnormal blood sugar before transplantation, kidneycirrhosis hepatic dysfunction, application of hormones and calcineurin inhibitor (CNI) etc. would increase the risk of PTDM [4-5]. There is little research on the long-term blood sugar variations and hazards following kidneytransplantation in China and most research focuses on a single factor analysis. Thus, it is particularly important to study the factors related to the occurrence and progression of PTDM for pathogenesis of PTDM and prevention of PTDM.

\section{Material and Methods}

\subsection{Object of Study}

422 patients who received kidneytransplantation in our hospital from January 2015 to December 2018 were collected. There were 307 males and 115 females. They were aged 18-75 years and 46.3 \pm 16.1 years on average. Any patients who used glucocorticoid before operation, had incomplete data, or died within 3 months were excluded. The primary diseases of patients were primary kidneycancer accompanied by kidneycirrhosis, 216 cases, primary kidneycancer, 103 cases, posthepatitic cirrhosis, 79 cases, and other rare types, 24 cases.

All patients were injected regularly with insulin by a micropump 3-5 days after operation to control the blood sugar and subsequently injected with insulin subcutaneously to control the blood sugar. The dosage of insulin was adjusted based on the blood sugar. Objective of blood sugar control: fasting blood sugar $8.10 \mathrm{mmol} / \mathrm{L}$ and $8.14 \mathrm{mmol} / \mathrm{L} 2 \mathrm{~h}$ after a meal.

\subsection{Method for Using Immunosuppression Medicines After Operation}

The preferred immunosuppressor was tacrolimus, FK506, which was to be taken orally at 2 days after operation at a dose of $8-20 \mathrm{mg} /$ day until the plasma drug concentration was reached; (cyclosporine-A, CsA would be used at a dose depending on the plasma concentration if the patients had severe mental symptoms after FK506 was administered. Rapamycin would be administered to partial patients if the plasma concentration failed to reach the standard or experienced renal insufficiency due to use of FK506. The dose and target concentration were similar to FK506. Considering the effect of rapamycin on wound healing, it could be generally applied only at least 1 month after transplantation.

\subsection{Variation Trend of Fasting Blood Sugar}

On the basis of pre-operative fasting blood sugar and in combination with the medical history, the patients were divided into Diabetes Mellitus (DM) Group, Group of Impaired Fasting Blood Glucose (IFG), and Group of Normal Fasting Blood Glucose (NFG). The 422 patients were analysed. 106 cases fell into Group DM accounting for $25.12 \%$; 118 cases fell into Group IFG accounting for $27.96 \%$; 198 cases fell into Group NFG accounting for $46.92 \%$. Based on analyses of the fasting blood sugar data 3, $6,9,12,24,36,48$, and 60 months after operation, the variation trends of fasting blood sugar in various groups were obtained. Comparisons were made for variations in fasting blood sugar in various groups before and after operation to determine presence or absence of any statistical difference.

\subsection{Diagnostic Criteria for PTDM}

Referring to the literature, [6], in the research, the kidneytransplantation patients with fasting blood sugar < $5.6 \mathrm{mmol} / \mathrm{L}$ were diagnosed as having normal fasting blood sugar (NFG); the kidneytransplantation patients with fasting blood sugar $\geq 5.6 \mathrm{mmol} / \mathrm{L}$ but $<7$. Ommol/L were diagnosed as having impaired fasting glucose (IFG); the kidneytransplantation patients with blood sugar > $17.8 \mathrm{mmol} / \mathrm{L}$ but $<11.1 \mathrm{mmol} / \mathrm{L}$ in the $2 \mathrm{~h}$ glucose tolerance test were diagnosed as having impaired glucose tolerance (IGT); the kidneytransplantation patients with fasting blood sugar $\geq 7.0 \mathrm{mmol} / \mathrm{L}$ or with blood sugar $3 \mathrm{~h}$ after a meal ( or OGTT $2 \mathrm{~h}$ blood sugar) $\geq 11.1 \mathrm{mmol} / \mathrm{L}$ were diagnosed with diabetes mellitus (DM). In addition, the patients were also diagnosed with diabetes if they had normal blood sugar but were using insulin or orally taking blood sugar lowering medicines.

\subsection{Data on Simplified Oral Glucose Tolerance Test (OGTT)}

Among the kidneytransplantation patients $\geq 3$ years after kidneytransplantation, the patients who were diagnosed with diabetes, died, and lost to follow-up were excluded. A simplified OGTT was conducted for the remaining 46 eligible patients with persistent long-term follow-up to detect the fasting blood sugar and insulin and the blood sugar and insulin $2 \mathrm{~h}$ after a meal and glycosylated hemoglobin and blood lipid and to calculate the HOMA index [7]. The formulae are as follows:

$$
\text { HOMA-IR=fasting blood sugar }(\mathrm{mmol} / \mathrm{L}) \times \text { fasting insulin }(\mathrm{uU} / \mathrm{mL}) \div 22.5
$$$$
\text { HOMA }-\beta=20 \times \text { fasting insulin }(\mathrm{uU} / \mathrm{mL}) \div(\text { fasting blood sugar }(\mathrm{mmoVL})-3.5)
$$

Based on the test results, the patients were divided into Normal Group, Group of Impaired Glucose Regulation (IGR), and Group of Post-Transplantation Diabetes Mellitus (PTDM).

\subsection{PTDM Occurrence and PTDM Pathogenesis}

Based on the fasting blood sugar of patients, an analysis was conducted for the PTDM occurrence 3 months, 6 months, 9 
months, 1 years, 3 years, and 5 years after operation; a glucose tolerance test was conducted for patients with FPG not meeting the diagnostic criteria for diabetes $3 \geq$ years after kidneytransplantation to determine fasting and $2 \mathrm{~h}$ blood sugar and insulin, evaluate the PTDM occurrence in kidneytransplantation patients with FPG not meeting the diagnostic criteria for diabetes $3 \geq$ years after operation, calculate the HOMA index, and preliminarily discuss the PTDM pathogenesis.

\subsection{Effect of Fasting Blood Sugar on the Survival Rate of Kidneytransplantation Patients}

Based on the preoperative fasting blood sugar and past medical history, the patients were divided into Group DM, Group IFG, and Group NFG. A survival curve was plotted to compare the difference of the survival rates among the three groups of patients.

\subsection{Statistical Methods}

The SPSS 13.0 was used as the statistical analysis software. All of the measurement data were expressed with mean \pm standard deviation and the enumeration data were expressed with numerical value and percentage. The t test and variance analysis (One-Way ANOVA) were conducted for the measurement data in the single factor analysis. $\mathrm{P}<0.05$ was considered statistically significant.

\section{Results}

\subsection{Variation Trend of Fasting Blood Sugar After Kidneytransplantation}

Variation trend of fasting blood sugar in patients before operation and within 1 year after operation: within 1 year after kidneytransplantation, the fasting blood sugar in Group DM decreased significantly compared with that before operation and the comparison between fasting blood sugar 6 , 9, and 12 months after operation and that before operation was statistically significant $(\mathrm{P}<0.05)$; the fasting blood sugar in Group IFG rose compared with that before operation and the variation was the most significant 12 months after operation. The comparison between fasting blood sugar after operation and that before operation was statistically significant $(\mathrm{P}<0.05)$; the fasting blood sugar in Group NFG significantly rose after 3 months and tended toward stability subsequently. The comparison between fasting blood sugar at different times after operation and that before operation was statistically significant $(\mathrm{P}<0.05)$. Pairwise comparisons of the variation trends among three groups $(\mathrm{P}<0.05)$.

Variation trend of fasting blood sugar in patients before operation and within 5 years after operation: within 1 year after operation, the fasting blood sugar in Group DM decreased significantly $(\mathrm{P}<0.05)$ and then exhibited an increasing trend, which reached the highest 3 years after operation and decreased 5 years after operation compared with that before operation; but no statistical significance was reached $(\mathrm{P}>0.05)$; the fasting blood sugar in Group IFG increased significantly 1 year after operation compared with that before operation $(\mathrm{P}<0.05)$ and then exhibited a slowdown trend; there was no statistical difference between fasting blood sugar 3 years after operation and that 5 years after operation $(\mathrm{P}>0.05)$; the fasting blood sugar in Group NFG increased significantly 1 year after operation compared with that before operation $(\mathrm{P}<0.05)$ and then maintained stability; it still increased significantly 5 years after operation compared with that before operation $(\mathrm{P}<0.05)$.

\subsection{Judging PTDM Occurrence After Kidneytransplantation Based on Fasting Blood Sugar}

Diabetes occurrence in pre-operative non-diabetic patients (i.e. preoperative Group IFG and NFG combined) 3, 6, 9, 12, 36 , and 60 months is shown in Table 1. The PTDM morbidity exhibited an overall decreasing trend with time. It reached the highest, $52.82 \%, 3$ months after operation; it significantly decreased to $30.95 \% 6$ months after operation and decreased slowly subsequently; it decreased to $20.75 \% 3$ years after operation and maintained stable subsequently. The chi-squared test for trend indicated that the PTDM morbidity exhibited an overall decreasing trend $(\mathrm{P}<0.05)$.

Table 1. PTDM Occurrence in Non-Diabetic Patients before kidneyTransplantation.

\begin{tabular}{llll}
\hline Post-Operation Time (months) & Total Number of Cases & Number of Patients & PTDM Morbidity (\%) \\
\hline 3 & 195 & 103 & 52.82 \\
6 & 126 & 39 & 30.95 \\
9 & 107 & 31 & 28.97 \\
12 & 81 & 24 & 29.63 \\
36 & 53 & 11 & 20.75 \\
60 & 37 & 8 & 21.62 \\
\hline
\end{tabular}

\subsection{Preliminary Evaluation of PTDM Pathogenesis Baed on the HOMA Index}

Table 2. OGTT Results of Partial Patients with Fasting Blood Sugar Failing to Meet the Diagnostic Criteria for Diabetes $\geq 3$ years after kidneyTransplantation.

\begin{tabular}{llll}
\hline Item & Normal Group $(\mathbf{n}=13)$ & Group IGR $(\mathbf{n}=\mathbf{2 2})$ & Group PTDM $(\mathbf{n = 1 2})$ \\
\hline Fasting Blood Sugar $(\mathrm{mmol} / \mathrm{L})$ & $5.26 \pm 0.33$ & $6.21 \pm 0.35$ & $7.16 \pm 0.81$ \\
Fasting Insulin $(\mathrm{Uu} / \mathrm{ml})$ & $5.13 \pm 0.29$ & $7.38 \pm 0.46$ & $5.36 \pm 0.41$ \\
2h-Blood Sugar (mmol/L) & $5.30 \pm 0.37$ & $7.81 \pm 0.59$ & $8.67 \pm 0.93$ \\
2h-Insulin (Uu/ml) & $27.16 \pm 4.31$ & $48.07 \pm 9.22^{*}$ & $50.25 \pm 11.34 *$ \\
\hline
\end{tabular}

Legend: Compared with the Normal group, ${ }^{*} \mathrm{P}<0.05$. 
A simplified OGTT was performed for 46 patients with their fasting blood sugar not meeting the diagnostic criteria for diabetes $\geq 3$ years after kidneytransplantation and the results were shown in Table 2. The fasting insulin level was the highest in Group IGR and the lowest in the normal blood sugar group. There was no significant difference based on pairwise comparisons among three groups but the fasting insulin level in Group IGR exhibited an increasing trend compared with the normal blood sugar group. No statistical significance was reached $(\mathrm{P}>0.05)$. The $2 \mathrm{~h}$-insulin was progressively increasing in the normal blood sugar group, Group IGR, and Group PTDM and there was a significant difference only between Group IGR and the normal blood sugar group $(\mathrm{P}<0.05)$. HOMA-IR was the highest in Group IGR followed by PTDM. It significantly increased in Group IGR compared with the normal blood sugar group $(\mathrm{P}<0.05)$, indicating that insulin resistance was present at the early stage of abnormal glucose metabolism after kidneytransplantation. HOMA- $\beta$ was progressively decreasing in the normal blood sugar group, Group IGR, and Group PTDM and HOMA- $\beta$ significantly decreased in Group PTDM in contrast to the normal blood sugar group and Group IGR $(\mathrm{P}<0.05)$, indicating that the functions of pancreatic $\beta$ cells were declining with aggravation of abnormal glucose metabolism after kidneytransplantation.

\subsection{Comparison of Survival Rates of Group DM, IFG, and $N F G$}

The average survival time and survival rate of Group NFG, IFG, and DM were decreasing in sequence. The survival rate of Group DM decreased significantly compared with that of Group NFG $(\mathrm{P}<0.05)$. The survival rate of Group IFG also decreased significantly compared with that of Group NFG $(\mathrm{P}<0.05)$. The survival rate of Group DM decreased compared with Group IFG but no statistical difference was reached $(\mathrm{P}>0.05)$.

\subsection{Comparison of Survival Rates and Post-operative Complications Between Group PTDM and Non-PTDM Groups}

The average survival time and survival rate of Group PTDM were significantly lower than those of non-PTDM groups $(\mathrm{P}<0.05)$. Compared with non-PTDM groups, the incidence rates of post-operative bacterial infection and chronic renal insufficiency were higher in Group PTDM and no statistical significance was reached $(\mathrm{P}<0.05)$. There was no significant difference in incidence rate among fungal infection, cytomegalovirus infection, post-operative fatty kidney $(\mathrm{P}>0.05)$. Table 3 .

Table 3. Comparison of Complications between Group PTDM and Non-PTDM Groups.

\begin{tabular}{llll}
\hline Post-Operative Complications & Non-PTDM Group & Group PTDM & P Value \\
\hline Bacterial Infection & 68 & 127 & 0.018 \\
Fungal Infection & 57 & 68 & 0.615 \\
Chronic Renal Insufficiency & 41 & 89 & 0.012 \\
Biliary Complication & 35 & 38 & 0.823 \\
Cytomegalovirus Infection & 10 & 15 & 0.711 \\
Postoperative Fatty Liver & 8 & 14 & 0.682 \\
\hline
\end{tabular}

\section{Discussion}

Based on the variation trend of fasting blood sugar, it is observed in the research that the fasting blood sugar of patients in Group DM before operation decreases compared with that before operation and the decrease in fasting blood sugar 6-24 months after operation exhibits a statistical difference, indicating that kidneytransplantation is good for improving patients' glycometabolism. In China, the majority of kidneytransplantation recipients are patients with chronic kidneydiseases. Chronic kidneydiseases are characterized in that various kidneydiseases lead to substantive damage to the kidneyand induce disturbance of carbohydrate metabolism, clinically manifested by hyperglycemia and decrease in glucose tolerance. The diabetes secondary to hepatic substantive damage is called hepatic diabetes [8-9]. The pathogenesis of hepatic diabetes is primarily insulin resistance. Insulin secretion insufficiency may occur with progression of the disease. Hyperinsulinemia is accompanied by endogenous insulin sensitivity decline. The decline in use of insulin by the surrounding tissues is more severe than the increase in endogenous glucose generated [10-11]. kidneytransplantation is able to improve insulin resistance resulted from kidneycirrhosis but not able to completely restore the normal functions [12-13]. Partial patients with pre-operative diabetes were diagnosed as having normal fasting blood sugar or damaged fasting blood sugar after operation, which is consistent with that reported in the literature [14-15]. The fasting blood sugar of patients in Group IFG and NFG exhibits an increasing trend after operation, which is significant 3 months after operation. Considering the use of hormones 3 months after operation, it is consistent with the variation trend of the PTDM morbidity.

The PTDM morbidity has been reported different in the literature, which is associated with the diagnostic criteria adopted in different studies. The course of disease may be 1 month or 6 months and the majority are judged on the basis of fasting blood sugar [16-17]. In the research, the ADA standard is used to make a judgement based on fasting blood sugar. The PTDM morbidity in kidneytransplantation patients reached the highest, $52.82 \%$, 3 months after operation, $29.63 \% 1$ year after 
operation, and $20.75 \% 3$ years after operation. With the prolonged time after transplant ion, the PTDM morbidity exhibits a decreasing trend and PTDM frequently occurs at an early stage after transplantation. A gradual decline in the PTDM morbidity may be due to the fact that the dosage of hormones and immunosuppressor is decreasing; the kidneyfunctions are recovering gradually following transplantation; stress factors are being relieved gradually etc.[18-19]. The definite causes still remain to be studied further.

The pathogenesis of PTDM has been reported different in the literature. The majority of the scholars have opined that the potential low insulin secretion of PTDM patients are aggravated by the immunosuppressor and their B cells are susceptible to anti-rejection medicines [20-22]. Research has also indicated that the state of insulin resistance is present in patients with terminal kidneydiseases; application of hormones further lowers the sensitivity of the peripheral insulin following transplantation; in addition, the insulin secretion defect caused by calcineurin inhibitor also accelerates the progression of PTDM [23-24]. Dukes et al. have conducted an OGTT for 36 renal transplantation patients treated with trimodality therapy dominated by CsA and found that the incidence rate of insulin resistance of patients with post-operative abnormal glucose metabolism is much higher than the incidence rate of $\mathrm{B}$ cell hypofunction and the minimum concentration of CsA is significantly associated with IR, which indicates that insulin resistance plays a more important role in PTDM than pancreatic B cell hypofunction. Similar conditions may also be present in kidneytransplantation patients [25]. In the research, it is observed that the HOMA-IR in Group IGR is significantly higher than that in the normal blood sugar group and also higher than that in Group PTDM, which indicates that insulin resistance is present at an early stage of abnormal glucose metabolism; however, the HOMA- $\beta$ is decreasing in sequence in the normal blood sugar group, Group IGR, and Group PTDM and the HOMA- $\beta$ decreases significantly in Group PTDM compared with the normal blood sugar group and Group IGR, which indicates that the functions of pancreatic B cells are declining progressively with aggravation of abnormal glucose metabolism.

There is a controversy over the effect of blood sugar on survival. Veroux et al. have reported that there is no significant difference in survival rate between Group PTDM with age and sex matching and the control group at 1,2, and 5 years, which may be associated with the small sample size [26]. A retrospective analysis by Dostalek et al. for 778 kidneytransplantation patients (half of them were complicated with Hepatitis C) has indicated that the survival rates of transplants and patients in Group PTDM decrease significantly [27]. Lorho et al. have reported that there is no significant difference in survival rate between diabetic and non-diabetic patients before kidneytransplantation but the survival rate in Group PTDM decreases significantly compared with that in Non-PTDM Groups [28]. Our research indicates that the survival rates in Group DM and IFG decrease significantly compared with that in Group NFG before operation; the survival rate in Group PTDM also decreases significantly compared with that in non-PTDM groups after operation, indicating that both the existing diabetes before kidneytransplantation and the emerging diabetes after kidneytransplantation significantly decrease the survival rate of patients and the pre-operative fasting blood sugar abnormality can reduce the survival rate of patients after operation.

Blood sugar can be affected by various factors such as infection, hormones, various stresses, and various medicines, including hypoglycemic agents etc. [29-30]. The fasting blood sugar collected may be partial if the above conditions are not recorded in detail. The research data are clinical follow-up visit data. The data on blood sugar $2 \mathrm{~h}$ after a meal is not subject to the analysis due to its incompleteness. The incidence rate of abnormal glucose metabolism may be underestimated to some extent. In conclusion, monitoring of the blood sugar of kidneytransplantation patients should not be ignored. With extensive application of kidneytransplantation in our hospital, the survival time of patients is extending gradually.

\section{Conclusion}

Research on large samples and long-term follow-up visits may be conducted on the basis of observation of glycometabolism status of kidneytransplantation patients to guide the prevention of PTDM in kidneytransplantation patients and long-term ideal control of blood sugar.

\section{References}

[1] Borda B. Lengyel C. et al. Post-transplant diabetes mellitus risk factors and effects on the function and morphology of the allograft [J]. Acta Physiol Hung, 2019, 99 (2): 206-15.

[2] Ali IH. Abderrahim E. et al. Morbidity and mortality in Tunisian patients with post-transplant diabetes mellitus [J]. Saudi J Kidney Dis Transpl, 2018, 24 (3): 583-6.

[3] Xu Y. Liang JX. et al. Prevalence and long-term glucose metabolism evolution of post-transplant diabetes mellitus in Chinese renal recipients [J]. Diabetes Res Clin Pract, 2018, 92 (1): 11-8.

[4] Choi JY. Kwon OJ. Post-transplant diabetes mellitus: is it associated with poor allograft outcomes in renal transplants?[J]. Transplant Proc, 2018, 45 (8): 2892-8.

[5] Courivaud C. Ladriere M. et al. Impact of pre-transplant dialysis modality on post-transplant diabetes mellitus after kidney transplantation [J]. Clin Transplant, 2018, 25 (5): 794-9.

[6] Madziarska K. Weyde W. et al. The increased risk of post-transplant diabetes mellitus in peritoneal dialysis-treated kidney allograft recipients [J]. Nephrol Dial Transplant, 2018, 26 (4): 1396-401.

[7] Dutkiewicz G. Domanski L. et al. Polymorphisms of superoxide dismutase, glutathione peroxidase and catalase genes in patients with post-transplant diabetes mellitus [J]. Arch Med Res, 2018, 41 (5): 350-5. 
[8] Niu YJ. Shen ZY. et al. Establishment of tacrolimus-induced diabetes in rat model and assessment of clinical treatments for post-transplant diabetes mellitus in kidneytransplant recipients [J]. Clin Lab, 2018, 59 (7): 869-74.

[9] Saemann MD. Krebs M. Thiazolidinediones in the treatment of patients with Post-Transplant-Hyperglycemia or new-onset diabetes mellitus after renal transplantation (NODAT) - A new therapeutic option? [J]. Wien Klin Wochenschr, 2017, 122 (7): 198-202.

[10] Demirci MS. Toz H. et al. Risk factors and consequences of post-transplant diabetes mellitus [J]. Clin Transplant, 2017, 24 (5): 170-7.

[11] Haider DG. Mittermayer F. et al. Postprandial blood glucose level in maintenance hemodialysis patients predicts post-transplant-diabetes-mellitus [J]. Exp Clin Endocrinol Diabetes, 2017, 118 (3): 200-4.

[12] Gomes MB. Cobas RA. et al. Post-transplant diabetes mellitus [J]. Diabetol Metab Syndr, 2019, 1 (1): 14-9.

[13] Bayes B. Moreso F. et al. Post-transplant diabetes mellitus depending on the pre-transplant dialysis technique $[\mathrm{J}]$. Nefrologia, 2018, 28 (6): 97-102.

[14] Hathout E. Alonso E. et al. Post-transplant diabetes mellitus in pediatric kidneytransplantation [J]. Pediatr Transplant, 2019, 13 (5): 599-605.

[15] Xu X. Ling Q. et al. Post-transplant diabetes mellitus in kidneytransplantation: Hangzhou experience [J]. Hepatobiliary Pancreat Dis In, 2018, 7 (5): 465-70.

[16] Fabrizi F. Messa P. et al. Hepatitis C virus infection and post-transplant diabetes mellitus among renal transplant patients: a meta-analysis [J]. Int J Artif Organs, 2018, 31 (8): 675-82.

[17] Ollech JE. Kramer MR. et al. Post-transplant diabetes mellitus in lung transplant recipients: incidence and risk factors [J]. Eur J Cardiothorac Surg, 2018, 33 (5): 844-8.

[18] Leung Ki EL. Venetz JP. et al. Cytomegalovirus infection and new-onset post-transplant diabetes mellitus [J]. Clin Transplant, 2017, 22 (2): 245-9.

[19] Pietrzak-Nowacka M. Safranow K. et al. Autosomal dominant polycystic kidney disease is not a risk factor for post-transplant diabetes mellitus. Matched-pair design multicenter study [J]. Arch Med Res, 2017, 39 (3): 312-9.

[20] Soliman AR. Fathy A. et al. Sitagliptin might be a favorable antiobesity drug for new onset diabetes after a renal transplant [J]. Exp Clin Transplant, 2018, 11 (6): 494-8.

[21] Elens L. Sombogaard F. et al. Single-nucleotide polymorphisms in P450 oxidoreductase and peroxisome proliferator-activated receptor-alpha are associated with the development of new-onset diabetes after transplantation in kidney transplant recipients treated with tacrolimus [J]. Pharmacogenet Genomics, 2018, 23 (12): 649-57.

[22] Bonet J. Martinez-Castelao A. et al. Metabolic syndrome in hemodialysis patients as a risk factor for new-onset diabetes mellitus after renal transplant: a prospective observational study [J]. Diabetes Metab Syndr Obes, 2018, 6: 339-46.

[23] Balgradean M. Cinteza E. et al. Post renal transplant type 2 diabetes mellitus in a case of familial juvenile nephrophthisis [J]. Maedica (Buchar), 2018, 8 (1): 26-9.

[24] Lankarani KB. Eshraghian A. et al. New Onset Diabetes and Impaired Fasting Glucose After kidneyTransplant: Risk Analysis and the Impact of Tacrolimus Dose [J]. Exp Clin Transplant, 2018, 7 (30): 591-6.

[25] Dukes JL. Seelam S. et al. Health-related quality of life in kidney transplant patients with diabetes [J]. Clin Transplant, 2018, 27 (5): 554-62.

[26] Veroux M. Tallarita T. et al. Conversion to sirolimus therapy in kidney transplant recipients with new onset diabetes mellitus after transplantation [J]. Clin Dev Immunol, 2018, 6: 526-30.

[27] Dostalek M. Sam WJ. et al. Diabetes mellitus reduces the clearance of atorvastatin lactone: results of a population pharmacokinetic analysis in renal transplant recipients and in vitro studies using human kidneymicrosomes [J]. Clin Pharmacokinet, 2019, 51 (9): 591-606.

[28] Lorho R. Hardwigsen J. et al. Regression of new-onset diabetes mellitus after conversion from tacrolimus to cyclosporine in kidneytransplant patients: results of a pilot study [J]. Clin Res Hepatol Gastroenterol, 2018, 35 (6): 482-8.

[29] Gallagher EJ. Courgi R. et al Resolution of insulin-requiring diabetes in a kidneytransplant recipient after treatment of a pheochromocytoma: case report and review of literature.[J]. Minerva Endocrinol, 2018, 36 (4): 341-5.

[30] Veldt BJ. Duarte-Rojo A. et al. Recipient IL28B polymorphism is an important independent predictor of posttransplant diabetes mellitus in kidneytransplant patients with chronic hepatitis C [J]. Am J Transplant, 2019, 12 (3): 737-44. 